\title{
Application of compound material alleviates saline and alkaline stress in cotton leaves through regulation of the transcriptome
}

\author{
Mengjie $\mathrm{An}^{\dagger}$, Xiaoli Wang ${ }^{\dagger}$, Doudou Chang, Shuai Wang, Dashuang Hong, Hua Fan and Kaiyong Wang*
}

\begin{abstract}
Background: Soil salinization and alkalinization are the main factors that affect the agricultural productivity. Evaluating the persistence of the compound material applied in field soils is an important part of the regulation of the responses of cotton to saline and alkaline stresses.

Result: To determine the molecular effects of compound material on the cotton's responses to saline stress and alkaline stress, cotton was planted in the salinized soil $\left(\mathrm{NaCl} 8 \mathrm{~g} \mathrm{~kg}^{-1}\right)$ and alkalized soil $\left(\mathrm{Na}_{2} \mathrm{CO}_{3} 8 \mathrm{~g} \mathrm{~kg}^{-1}\right)$ after application of the compound material, and ion content, physiological characteristics, and transcription of new cotton leaves at flowering and boll-forming stage were analyzed. The results showed that compared with saline stress, alkaline stress increased the contents of $\mathrm{Na}^{+}, \mathrm{K}^{+}, \mathrm{SOD}$, and MDA in leaves. The application of the compound material reduced the content of $\mathrm{Na}^{+}$but increased the $\mathrm{K}^{+} / \mathrm{Na}^{+}$ratio, the activities of SOD, POD, and CAT, and REC. Transcriptome analysis revealed that after the application of the compound material, the $\mathrm{Na}^{+} / \mathrm{H}^{+}$exchanger gene in cotton leaves was down-regulated, while the $\mathrm{K}^{+}$transporter, $\mathrm{K}^{+}$channel, and POD genes were up-regulated. Besides, the down-regulation of genes related to lignin synthesis in phenylalanine biosynthesis pathway had a close relationship with the ion content and physiological characteristics in leaves. The quantitative analysis with PCR proved the reliability of the results of RNA sequencing.

Conclusion: These findings suggest that the compound material alleviated saline stress and alkaline stress on cotton leaves by regulating candidate genes in key biological pathways, which improves our understanding of the molecular mechanism of the compound material regulating the responses of cotton to saline stress and alkaline stress.
\end{abstract}

Keywords: Alkalinization, Antioxidant, Compound material, $\mathrm{K}^{+} / \mathrm{Na}^{+}$ratio, Lignin biosynthesis, Salinization

\section{Background}

Soil salinization and alkalization are the main environmental factors that limit crop growth and yield [1]. Salinized soil and alkalized soils are widely distributed in arid and semi-arid regions around the world [2, 3], and the stresses caused by salinized and alkalized soils directly affect the ion balance of plant cells [4], which in

\footnotetext{
*Correspondence: wky20@163.com

${ }^{\dagger}$ Mengjie An and Xiaoli Wang contributed equally to this work. Agricultural College, Shihezi University, Shihezi, Xinjiang 832000, People's Republic of China
}

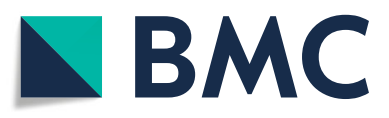

( The Author(s). 2020 Open Access This article is licensed under a Creative Commons Attribution 4.0 International License, which permits use, sharing, adaptation, distribution and reproduction in any medium or format, as long as you give appropriate credit to the original author(s) and the source, provide a link to the Creative Commons licence, and indicate if changes were made. The images or other third party material in this article are included in the article's Creative Commons licence, unless indicated otherwise in a credit line to the material. If material is not included in the article's Creative Commons licence and your intended use is not permitted by statutory regulation or exceeds the permitted use, you will need to obtain permission directly from the copyright holder. To view a copy of this licence, visit http://creativecommons.org/licenses/by/4.0/. The Creative Commons Public Domain Dedication waiver (http://creativecommons.org/publicdomain/zero/1.0/) applies to the data made available in this article, unless otherwise stated in a credit line to the data.

turn affects physiological homeostasis [5, 6]. Many studies have shown that saline stress and alkaline stress are two different types of stress for plants [7], and the effect of alkaline stress on plants is more severe than that of saline stress [8]. Saline stress is mainly caused by neutral salt, while alkaline stress is mainly caused by alkaline salt [9]; saline stress generally causes ionic damage and osmotic stress in plants [10], and alkaline stress not only causes the above-mentioned damage to plants, but also increases the $\mathrm{pH}$ in plants [11]. Previous studies have found that the application of exogenous materials is one 
of the effective ways to regulate the responses of crops to saline stress and alkaline stress [12, 13]. Chemical modification can be used to regulate the responses of crops to saline stress and alkaline stress through replacing $\mathrm{Na}^{+}$in soil by applying inorganic salts (e.g. calcium, aluminum sulfate, ferrous sulfate, etc.), or organic compounds (e.g. lignosulfonate, polyacrylamide, etc.), thus reducing soil salinity and alkalinity, promoting plant growth, and improving crop quality. Gong, et al. [12] found that melatonin regulated the enzyme activity and biosynthesis of polyamines and improved the tolerance of plants to alkaline stress. Faghih, et al. [13] showed that spraying salicylic acid and methyl jasmonate on the leaves could improve the defense system and antioxidant capacity of strawberry under salt stress. Therefore, it is of great importance to study the effects of the application of exogenous materials on the responses of plants to saline stress and alkaline stress.

Cotton (Gossypium spp.) is one of the most important economic crops in the world, among which Gossypium hirsutum L. has been widely planted and its planting area accounts for more than $95 \%$ of the global planting area. Although cotton is salt tolerant, its growth is affected by saline stress and alkaline stress [14]. According to reports, saline stress and alkaline stress affect seed germination, seedling growth, root growth, flowering, and boll number of cottons, resulting in a loss of yield [15-17]. Facing an increasing global demand for cotton, studies on regulating the damages caused by saline stress and alkaline stress on cotton have gained momentum [18]. Several genes regulating the response to saline and alkaline stress in cotton have been discovered. For example, ion channels and transporters can mitigate $\mathrm{Na}^{+}$ toxicity and $\mathrm{K}^{+} / \mathrm{Na}^{+}$ratio homeostasis, and overexpression of NHX1 or SOS1 in cotton can improve salt tolerance [19]. GhSOS3 and GhCBL10 are involved in regulating the responses to saline stress and alkaline stress, and the GhSOS3/GhCBL10-SOS2 network also plays a central role in $G$. hirsutum responses to saline stress and alkaline stress [20]. Besides, overexpression of the OSCU/Zn-SOD gene can improve the detoxification capacity of reactive oxygen species and improve the salt tolerance [21]. However, most of the previous studies were conducted through pot experiments or indoor culture experiments, and few was conducted through field experiments. Field experiments make the growth of crops very close to their natural growth, which can truly reflect the growth law of crops.

In this study, RNA-seq was used to analyze the transcriptional changes of cotton leaves under saline stress and alkaline stress, and to elucidate the molecular effects of the compound material on the improving saline and alkaline tolerance. We analyzed many genes related to plant antioxidant defense, $\mathrm{K}^{+} / \mathrm{Na}^{+}$ratio transport, and lignin biosynthesis, and these genes may be involved in the regulation of the responses of cotton to saline stress and alkaline stress by the compound material. The main purposes of this experiment are: (1) to determine the differences in the responses of cotton to saline stress and alkaline stress; (2) to determine the differences in the effects of the compound material on $\mathrm{K}^{+}, \mathrm{Na}^{+}$, and physiological characteristics of cotton leaves; and (3) to provide insights on the relevant genes in the process of the regulation of the responses of cotton to saline stress and alkaline stress by the compound material.

\section{Results}

$\mathrm{K}^{+}, \mathrm{Na}^{+}$, and physiological characteristics of cotton leaves The $\mathrm{K}^{+}$and $\mathrm{Na}^{+}$contents of leaves for the $\mathrm{Na}_{2} \mathrm{CO}_{3}$ treatments (CK-J and P-J treatments) were higher than those for the $\mathrm{NaCl}$ treatments (CK-Y and P-Y treatments) (Fig. 1a). The contents of $\mathrm{K}^{+}$and $\mathrm{Na}^{+}$for the CK-J treatment were increased by $30.54 \%(P<0.05)$ and $21.20 \%(P<0.05)$, respectively compared with those for the CK-Y treatment (Fig. 1a). The $\mathrm{K}^{+} / \mathrm{Na}^{+}$ratio for the $\mathrm{P}-\mathrm{Y}$ and $\mathrm{P}-\mathrm{J}$ treatments were increased $(P<0.05)$ and the $\mathrm{Na}^{+}$contents were decreased $(P>0.05)$ after the application of compound material compared with those for the controls (CK-Y and CK-J treatments). For the P-Y treatment, there was no significant difference in the $\mathrm{K}^{+}$content; the $\mathrm{Na}^{+}$content was decreased $(P>0.05)$, and the $\mathrm{K}^{+} / \mathrm{Na}^{+}$ratio was increased $(P>0.05)$, compared with those for the CK-Y treatment (Fig. 1a). For the P-J treatment, there was no significant difference in the $\mathrm{K}^{+}$content; the $\mathrm{Na}^{+}$content was decreased by $18.26 \%(P>$ $0.05)$, and the $\mathrm{K}^{+} / \mathrm{Na}^{+}$ratio was increased by $37.11 \%$ $(P<0.05)$ compared with those for the CK-J treatment (Fig. 1a). Meanwhile, the $\mathrm{K}^{+}$and $\mathrm{Na}^{+}$contents and the $\mathrm{K}^{+} / \mathrm{Na}^{+}$ratio for the P-J treatment were increased by $35.14 \%(P<0.05), 14.11 \%(P>0.05)$, and $18.27 \%(P<$ 0.05), respectively compared with those for the P-Y treatment (Fig. 1a).

The SOD activity for the CK-J treatment was increased by $46.29 \%(P<0.05)$, while the POD and CAT activities were decreased by $4.09 \%(P<0.05)$ and $27.60 \%(P<$ 0.05), respectively compared with those for the CK-Y treatment (Fig. 1b). The antioxidant enzyme activity for the P-Y and P-J treatments were increased compared with the controls (CK-Y and CK-J treatments) (Fig. 1b). The SOD, POD, and CAT activities and REC for the P-Y treatment were increased by 45.24, 44.71, 29.11, and $24.02 \%$, respectively $(P<0.05)$, while there was no significant difference in the MDA content, compared with those for the CK-Y treatment. The POD and CAT activities for the P-J treatment were increased by $15.10 \%(P<$ $0.05)$ and $22.66 \%(P>0.05)$, respectively, and there was no significant difference in the SOD activity and REC content, compared with those for the CK-J treatment 

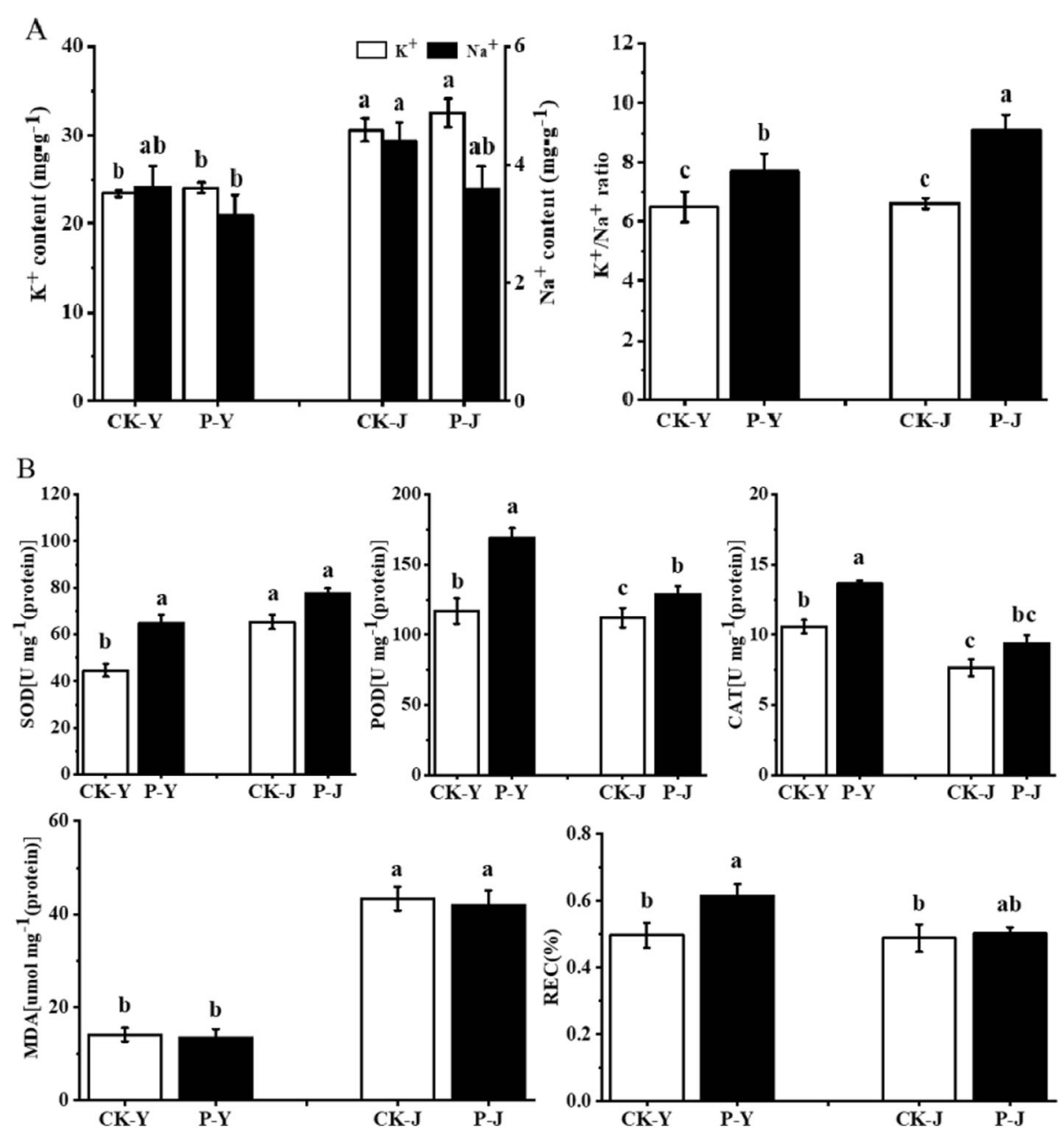

Fig. 1 Effect of the application of compound material on $\mathrm{K}^{+}$and $\mathrm{Na}^{+}$contents and $\mathrm{K}^{+} / \mathrm{Na}^{+}$ratio $(\mathbf{a})$, antioxidative enzymes activity, and $\mathrm{MDA}$ and REC contents (b) in leaves

(Fig. 1b). Meanwhile, there was no significant difference in the SOD activity and REC for the P-J treatment $(P>$ $0.05)$, and the POD and CAT activities were decreased by $23.72 \%(P<0.05)$ and $31.22 \%(P<0.05)$, respectively, compared with those for the P-Y treatment (Fig. 1b).

\section{Overview of the Transcriptomic responses}

Transcriptome of each sample was sequenced on Illumina paired-end sequencing platform. The number of reads generated ranged from 39 to 48 million, with a mean of 44 million reads for each sample. The reads were mapped onto the cotton reference transcriptome. The mapping ratio varied from 53.60 to $67.40 \%$, with a mean of $64.11 \%$. The counts of mapped reads were summarized at gene level (Additional file 1: Table S1, Additional file 2: Figure S1). The principal component analyses (PCA) was performed based on the gene counts (Additional file 3: Figure S2). The results showed that samples from $\mathrm{NaCl}$ and $\mathrm{Na}_{2} \mathrm{CO}_{3}$ treatments were clearly separated on the PC2 dimension, whereas the modified and unmodified samples were separated by at PC1 dimension. To verify the accuracy of RNA-seq data, six genes were randomly selected for quantitative RT-PCR (qRT-PCR) analysis. The expression abundances estimated by qRT-PCR and RNA-seq were highly correlated $\left(R^{2}=0.80\right.$, Additional file 4: Figure $\left.S 3\right)$, indicating that the RNA-seq results were suitable for the subsequent analysis.

\section{Differentially expressed genes}

To determine the differences of transcriptional responses to the treatments, differentially expressed genes (DEGs) were identified by pair-wise comparisons of the samples. Compared with the CK-Y treatment, 386 genes were up-regulated and 275 genes were down-regulated for the CK-J treatment (Fig. 2a). A total of 1937 and 


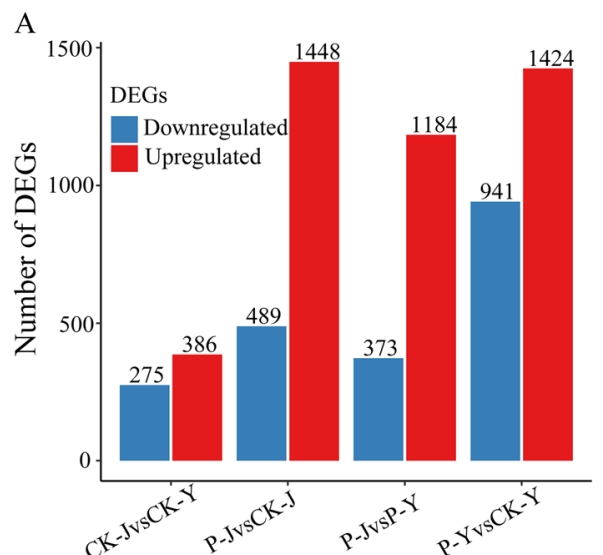

B

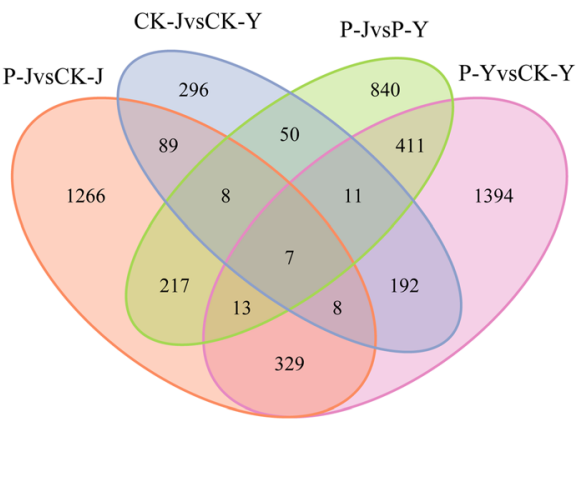

Fig. 2 Transcriptome analysis of cotton leaves in response to the application of compound material regulating saline stress and alkaline stress. Numbers of DEGs identified in cotton leaves (a). Venn diagram of DEGs (b)

2365 DEGs were identified for the $\mathrm{Na}_{2} \mathrm{CO}_{3}$ treatments (CK-J and P-J treatments) and $\mathrm{NaCl}$ treatments (CK-Y and P-Y treatments), respectively (Fig. 2a). These results indicated that the expression patterns of more genes for $\mathrm{NaCl}$ treatments were altered compared with the $\mathrm{Na}_{2} \mathrm{CO}_{3}$ treatments. Compared with the CK-Y treatment, 1424 genes were up-regulated and 941 genes were down-regulated for the P-Y treatment. Compared with the CK-J treatment, 1448 genes were up-regulated and 489 genes were down-regulated for the P-J treatment (Fig. 2a). Compared with the P-Y treatment, 1184 genes for the P-J treatment were up-regulated and 373 genes were down-regulated. Venn diagram was draw to identify the common and specific DEGs. The results showed that there were 7 common differentially expressed genes for the four treatments (Fig. 2b).

\section{Enrichment analysis}

GO enrichment analysis was performed on the DEGs identified in response to the compound material. For $\mathrm{NaCl}$ treatments (Fig. 3a), the top enriched GO terms for BP category were metal ion transport (GO:0030001), signal transduction (GO:0035556), and protein ubiquitination (GO:0016567), those for CC were extracellular region (GO:0005576), nucleosome (GO:0000786), and microtubule (GO:0005874), and those for MF were iron ion binding (GO:0005506), oxidoreductase activity (GO: 0016705), and hydrolase activity (GO:0004553). For $\mathrm{Na}_{2} \mathrm{CO}_{3}$ treatments (Fig. 3b), the top enriched GO terms for BP were metal DNA replication (GO:0006260), microtubule-based movement (GO:0007018), and metal ion transport (GO:0030001), those for CC were nucleosome (GO:0000786), MCM complex (GO:0042555), and microtubule (GO:0005874), and those for MF were protein heterodimerization activity (GO:0046982), iron ion binding (GO:0005506), and microtubule binding (GO: 0008017). For the controls (Fig. 3c), the top enriched GO terms for BP were signal transduction (GO: 0007165), lipid metabolic process (GO:0006629), and cell wall modification (GO:0042545), those for CC were cytoplasm (GO:0005737), integral component of plasma membrane (GO:0005887), and apoplast (GO:0048046), and those for MF were iron ion binding (GO:0005506), oxidoreductase activity, acting on paired donors (GO: 0016705), and sequence-specific DNA binding (GO: 0043565). For compound material treatments (Fig. 3d), the top enriched GO terms for BP were signal transduction (GO:0007165), lipid metabolic process (GO: 0006629), and metal ion transport (GO:0030001), those for CC were cytoplasm (GO:0005737), apoplast (GO: 0048046), and extracellular region (GO:0005576), and those for MF were sequence-specific DNA binding (GO: 0043565), calcium ion binding (GO:0005509), and iron ion binding (GO:0005506).

To further understand the molecular interactions among the DEGs, KEGG enrichment analysis was carried out. The results showed phenylpropanoid biosynthesis, pertussis, and brassinosteroid biosynthesis pathways were significantly enriched in $\mathrm{NaCl}$ treatments (CK-Y and P-Y treatments) (Additional file 5: Figure $\mathrm{S} 4 \mathrm{~A}) ;$ systemic lupus erythematosus and alcoholism pathways were significantly enriched in $\mathrm{Na}_{2} \mathrm{CO}_{3}$ treatments (CK-J and P-J treatments) (Additional file 5: Figure S4B); phenylpropanoid biosynthesis, glycerolipid metabolism, amino sugar and nucleotide sugar metabolism, and pentose and glucuronate interconversions pathways were significantly enriched in the controls (CK-J and CK-Y treatments) (Additional file 5: Figure S4C); phenylpropanoid biosynthesis and alpha-Linolenic acid metabolism pathways were significantly enriched in 

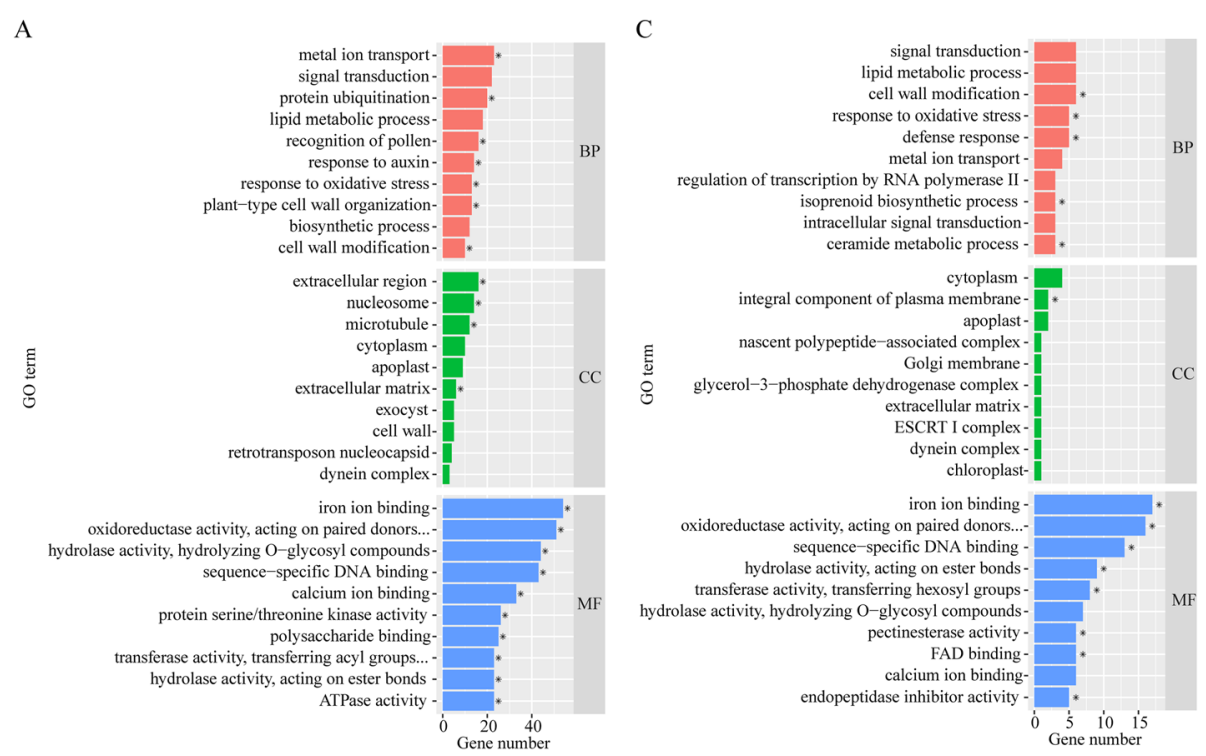

B

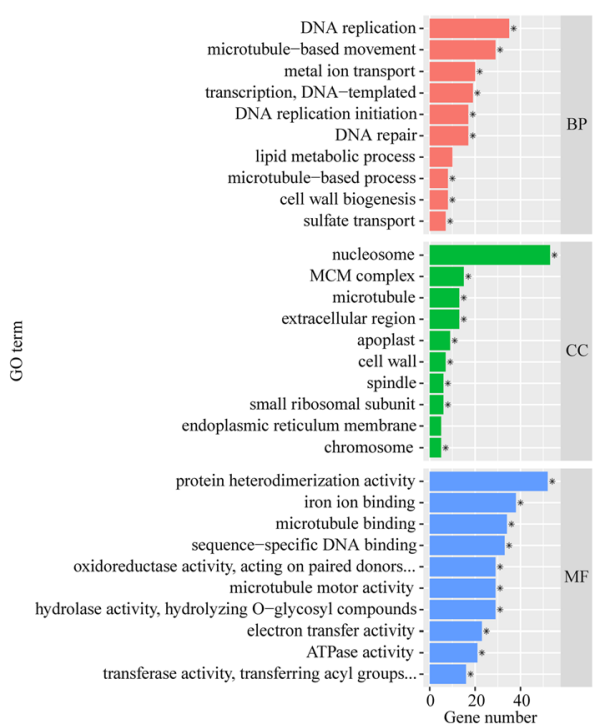

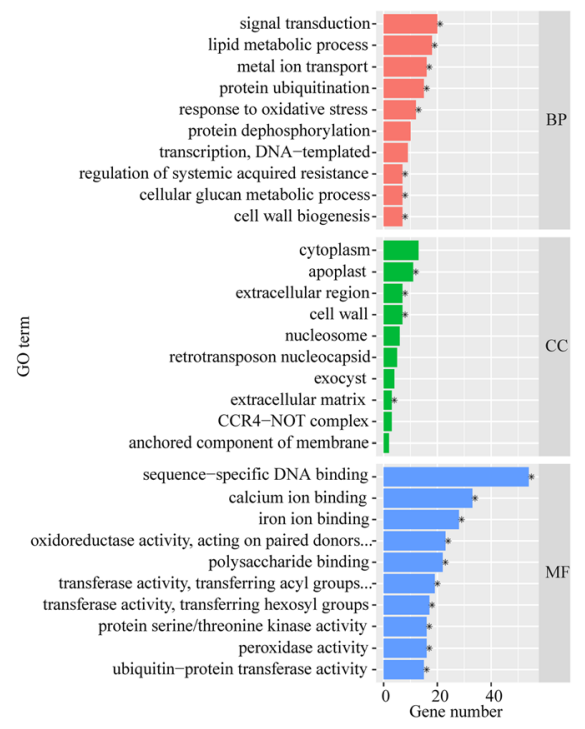

Fig. $3 \mathrm{GO}$ enrichment analysis of DEGs. The top 10 enriched $\mathrm{GO}$ terms in $\mathrm{NaCl}$ treatments (CK-Y and P-Y treatments). The top 10 enriched GO terms in $\mathrm{Na}_{2} \mathrm{CO}_{3}$ treatments (CK-J and P-J treatments) (a); The top 10 enriched GO terms in the controls (CK-J and CK-Y treatments) (b); The top 10 enriched GO terms in compound material treatments (P-J and P-Y treatments) (c); BP, CC, and MF represent biological process, cellular component, and molecular function, respectively (d). The asterisks represent the significant level of 0.05

compound material treatments (P-J and P-Y treatments) (Additional file 5: Figure S4D).

\section{Response of the salt ion transporter in cotton leaves}

The transporter-mediated salt ion balance in cotton leaves is an important part involved in the regulation of the responses of cotton to saline stress and alkaline stress by compound material. For $\mathrm{NaCl}$ treatments (CK$\mathrm{Y}$ and $\mathrm{P}-\mathrm{Y}$ treatments), $\mathrm{K}^{+}$transporter and $\mathrm{K}^{+}$channel genes were significantly regulated by the compound material, and four up-regulated $\mathrm{K}^{+}$channel genes ( $\mathrm{GH}$ A13G1568, GH_D01G0882, GH_D13G1517, and GH_ A01G0868) were identified. Besides, one $\mathrm{K}^{+}$transporter gene (GH_D08G2294) was up-regulated, and one sodium/hydrogen exchanger gene (GH_A09G0801) was down-regulated (Table 1). For $\mathrm{Na}_{2} \mathrm{CO}_{3}$ treatments (CK-J and P-J treatments), the expression levels of genes related to $\mathrm{K}^{+}$transporter (GH_D05G2808) and $\mathrm{K}^{+}$channel (GH_A01G0868, GH_D01G0882, and GH_D13G1517) changed significantly, and all were up-regulated (Table 1). 
Table 1 Expression patterns of DEGs involved in salt ions transport

\begin{tabular}{llllll}
\hline & Gene ID & log2FC & P value & Padj & Description \\
\hline CK-Y vs. P-Y & GH_A09G0801 & -1.2 & 0.04993 & 0.83714 & sodium/hydrogen exchanger 3 \\
& GH_D08G2294 & 1.31 & 0.00057 & 0.15126 & potassium transporter 1 \\
& GH_A13G1568 & 2.49 & 0.00742 & 0.55377 & two-pore potassium channel 1 \\
& GH_D01G0882 & 2.67 & 0.01501 & 0.69433 & two-pore potassium channel 1 \\
& GH_D13G1517 & 2.85 & 0.00823 & 0.57328 & two-pore potassium channel 1 \\
& GH_A01G0868 & 2.99 & 0.00726 & 0.55086 & two-pore potassium channel 1 \\
CK-J vs. P-J & GH_A01G0868 & 2.20 & 0.04683 & 0.98810 & two-pore potassium channel 1 \\
& GH_D01G0882 & 2.35 & 0.03191 & 0.93991 & two-pore potassium channel 1 \\
& GH_D13G1517 & 2.55 & 0.01693 & 0.82443 & two-pore potassium channel 1 \\
P-J vs. P-Y & GH_D05G2808 & 2.03 & 0.00451 & 0.57112 & potassium transporter 2 \\
\hline
\end{tabular}

For compound material treatments (P-J and P-Y treatments), one $\mathrm{K}^{+}$channel gene (GH_A05G1107) was downregulated (Table 1 ).

\section{Regulation of antioxidative defense in cotton leaves}

Many DEGs in cotton leaves were significantly enriched in oxidoreductase activity Go term. Eight peroxidase genes (GH_A06G1119, GH_D11G2319, GH_D10G1060, GH_A12G2651, GH_A05G0628, GH_D10G1977, GH_ D06G1268, and GH_A06G1247) for $\mathrm{NaCl}$ treatments were up-regulated, and three peroxidase genes (GH_ A05G4223, GH_A06G1247, and GH_A05G0628) for $\mathrm{Na}_{2} \mathrm{CO}_{3}$ treatments were up-regulated. Besides, one peroxidase gene (GH_A05G1582) for compound material treatments was down-regulated, and five peroxidase gene (GH_A03G1283, GH_D03G1634, GH_D04G0154, GH_ D03G1633, and GH_D08G2611) was up-regulated. One peroxidase gene (GH_D05G1612) for the controls was down-regulated, and one peroxidase gene (GH_ D10G1977) was up-regulated (Table 2).

\section{Analysis of correlation between transcription genes of $\mathrm{K}^{+}$, $\mathrm{Na}^{+}$, and physiological characteristics}

The correlation coefficients $(r)$ between transcription genes of $\mathrm{K}^{+}, \mathrm{Na}^{+}$, and physiological characteristics and results of significance tests are shown in Fig. 4. GH A09G0801 was positively correlated with $\mathrm{Na}^{+}$content $(P<0.05)$; GH_A13G1568, GH_D01G0882, GH_ D13G1517, GH_A01G0868, and GH_D05G2808 were positively correlated with $\mathrm{K}^{+} / \mathrm{Na}^{+}$ratio $(P<0.05)$ (Fig. 4a). GH_A06G1119, GH_D10G1060, GH_A12G2651, GH_ D10G1977, GH_D06G1268, and GH_A06G1247 were positively correlated with SOD activity $(P<0.05)$; $\mathrm{GH}_{-}$ A06G1119 $(P<0.05)$, GH_D10G1060 $(P<0.01)$, and GH A05G1582 $(P<0.01)$ were positively correlated with POD activity; GH_D10G1060 $(P<0.05)$ and GH_A05G1582 $(P<0.01)$ were positively correlated with CAT activity;
GH_A03G1283 and GH_D03G1634 were positively correlated with MDA content $(P<0.01)$; GH_A12G2651 $(P<$ 0.05), GH_D10G1977 $(P<0.05)$, GH_A06G1119 $(P<$ $0.01), G H \_D 10 G 1060(P<0.01)$, and GH_A05G1582 $(P<$ 0.01 ) were positively correlated with REC (Fig. 4b).

\section{DEGs involved in the phenylpropanoid biosynthesis pathway}

The expression of the genes involved in phenylpropanoid biosynthesis (https://www.kegg.jp/dbget-bin/www_ bget?map00940) of cotton leaves in response to the application of the compound material was analyzed (Fig. 5). For $\mathrm{NaCl}$ treatments, the DEGs involved in betaglucosidase (EC:3.2.1.21), coniferyl-alcohol glucosyltransferase (EC:2.4.1.111), and coniferyl-aldehyde dehydrogenase (EC:1.2.1.68) were up-regulated, while DEGs involved in scopoletin glucosyltransferase (EC:2.4.1.128), caffeic acid 3-O-methyltransferase (EC:2.1.1.68), ferulate-5-hydroxylase (EC:1.14.-.-), 4-coumarate--CoA ligase (EC:6.2.1.12), shikimate O-hydroxycinnamoyl transferase (EC:2.3.1.133), cinnamyl-alcohol dehydrogenase (EC:1.1.1.195), and peroxidase (EC:1.11.1.7) were down-regulated (Fig. 5a). For $\mathrm{Na}_{2} \mathrm{CO}_{3}$ treatments, the DEGs involved in ferulate-5-hydroxylase (EC:1.14.-.-) were up-regulated, while DEGs involved in shikimate $\mathrm{O}$ hydroxycinnamoyl transferase (EC:2.3.1.133) and peroxidase (EC:1.11.1.7) were down-regulated (Fig. 5b). For the controls, the DEGs involved in phenylalanine ammonia-lyase (EC:4.3.1.24), scopoletin glucosyltransferase (EC:2.4.1.128), and 4-coumarate--CoA ligase (EC: 6.2.1.12) were up-regulated, while DEGs involved in shikimate O-hydroxycinnamoyl transferase (EC:2.3.1.133), ferulate-5-hydroxylase (EC:1.14.-.-), coniferyl-aldehyde dehydrogenase (EC:1.2.1.68), and peroxidase (EC: 1.11.1.7) were down-regulated (Fig. 5c). For compound material treatments, the DEGs involved in phenylalanine ammonia-lyase (EC:4.3.1.24), feruloyl-CoA 6-hydroxylase 
Table 2 Expression patterns of DEGs involved in peroxidase

\begin{tabular}{|c|c|c|c|c|c|}
\hline & Gene ID & $\log 2 \mathrm{FC}$ & $P$ value & Padj & Description \\
\hline \multirow[t]{8}{*}{ CK-Y vs. P-Y } & GH_A06G1119 & 3.29 & 0.04162 & 0.81913 & peroxidase A2 \\
\hline & GH_D11G2319 & 17.66 & 0.00005 & 0.02426 & peroxidase A2 \\
\hline & GH_D10G1060 & 2.50 & 0.04006 & 0.81328 & peroxidase 50 \\
\hline & GH_A12G2651 & 2.57 & 0.01132 & 0.63957 & peroxidase 5 \\
\hline & GH_A05G0628 & 4.46 & 0.03935 & 0.81251 & peroxidase 46 \\
\hline & GH_D10G1977 & 19.80 & 0.00000 & 0.00046 & peroxidase 29 \\
\hline & GH_D06G1268 & 4.54 & 0.00327 & 0.39170 & peroxidase 12 \\
\hline & GH_A06G1247 & 3.44 & 0.00624 & 0.52647 & peroxidase 12 \\
\hline \multirow[t]{3}{*}{ CK-J vs. P-J } & GH_A05G4223 & 3.40 & 0.01666 & 0.82443 & peroxidase $\mathrm{P} 7$ \\
\hline & GH_A06G1247 & 3.85 & 0.00266 & 0.47075 & peroxidase 12 \\
\hline & GH_A05G0628 & 4.35 & 0.04211 & 0.97147 & peroxidase 46 \\
\hline \multirow[t]{6}{*}{ P-J vs. P-Y } & GH_A05G1582 & -2.30 & 0.04592 & 1.00000 & peroxidase 19 \\
\hline & GH_A03G1283 & 1.42 & 0.03043 & 1.00000 & peroxidase 3 \\
\hline & GH_D03G1634 & 1.76 & 0.02381 & 0.96048 & peroxidase 4 \\
\hline & GH_D04G0154 & 2.85 & 0.01578 & 0.85903 & peroxidase $\mathrm{P} 7$ \\
\hline & GH_D03G1633 & 5.85 & 0.01184 & 0.78791 & peroxidase 4 \\
\hline & GH_D08G2611 & 8.65 & 0.01451 & 0.84244 & peroxidase 53 \\
\hline \multirow[t]{2}{*}{ CK-J vs. CK-Y } & GH_D05G1612 & -1.74 & 0.01021 & 1.00000 & peroxidase 19 \\
\hline & GH_D10G1977 & 17.04 & 0.00002 & 0.02101 & peroxidase 29 \\
\hline
\end{tabular}

(EC:1.14.11.61), scopoletin glucosyltransferase (EC: 2.4.1.128), caffeic acid 3-O-methyltransferase (EC: 2.1.1.68), 4-coumarate--CoA ligase (EC:6.2.1.12), shikimate O-hydroxycinnamoyl transferase (EC:2.3.1.133), and caffeic acid 3-O-methyltransferase (EC:2.1.1.68) were up-regulated, while DEGs involved in ferulate-5hydroxylase (EC:1.14.-.-) and peroxidase (EC:1.11.1.7) were down-regulated (Fig. 5d).

\section{Discussion}

Under saline stress and alkaline stress, excessive $\mathrm{Na}^{+}$will accumulate in plant leaves, inhibiting the transport of $\mathrm{K}^{+}$ and causing $\mathrm{K}^{+}$and $\mathrm{Na}^{+}$ion imbalance in plant cells [22]. However, the regulations of ion balance are different under saline stress and alkaline stress. Wang, et al. [9] showed that the $\mathrm{Na}^{+}$content under alkaline stress was greater than that under saline stress in pot

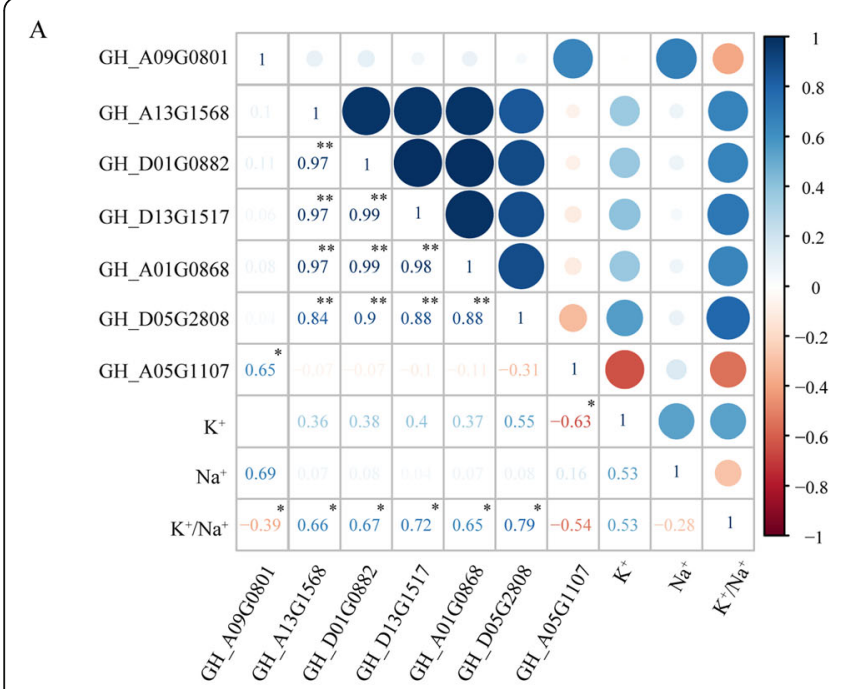

B

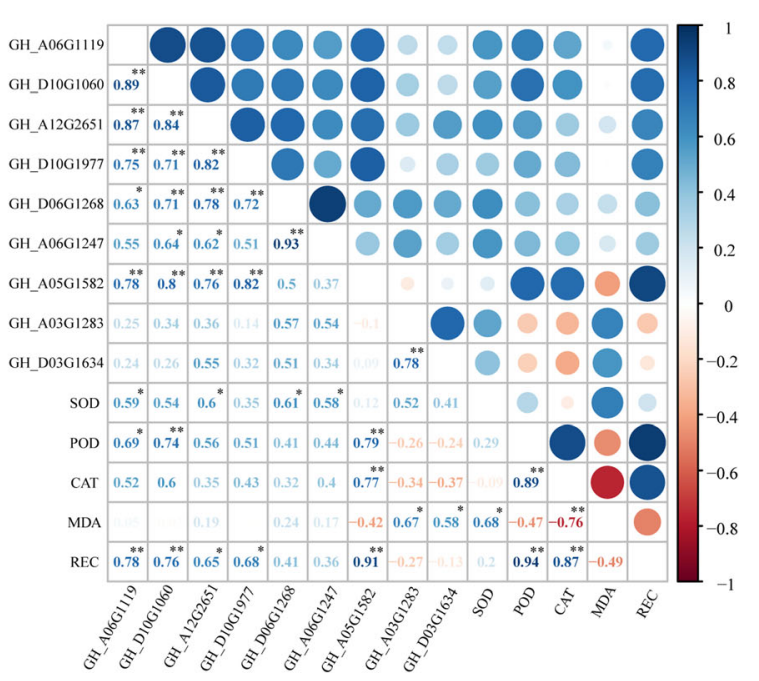

Fig. 4 Correlation analysis between transcription genes of $\mathrm{K}^{+}, \mathrm{Na}^{+}(\mathbf{a})$ and physiological characteristics (b) 


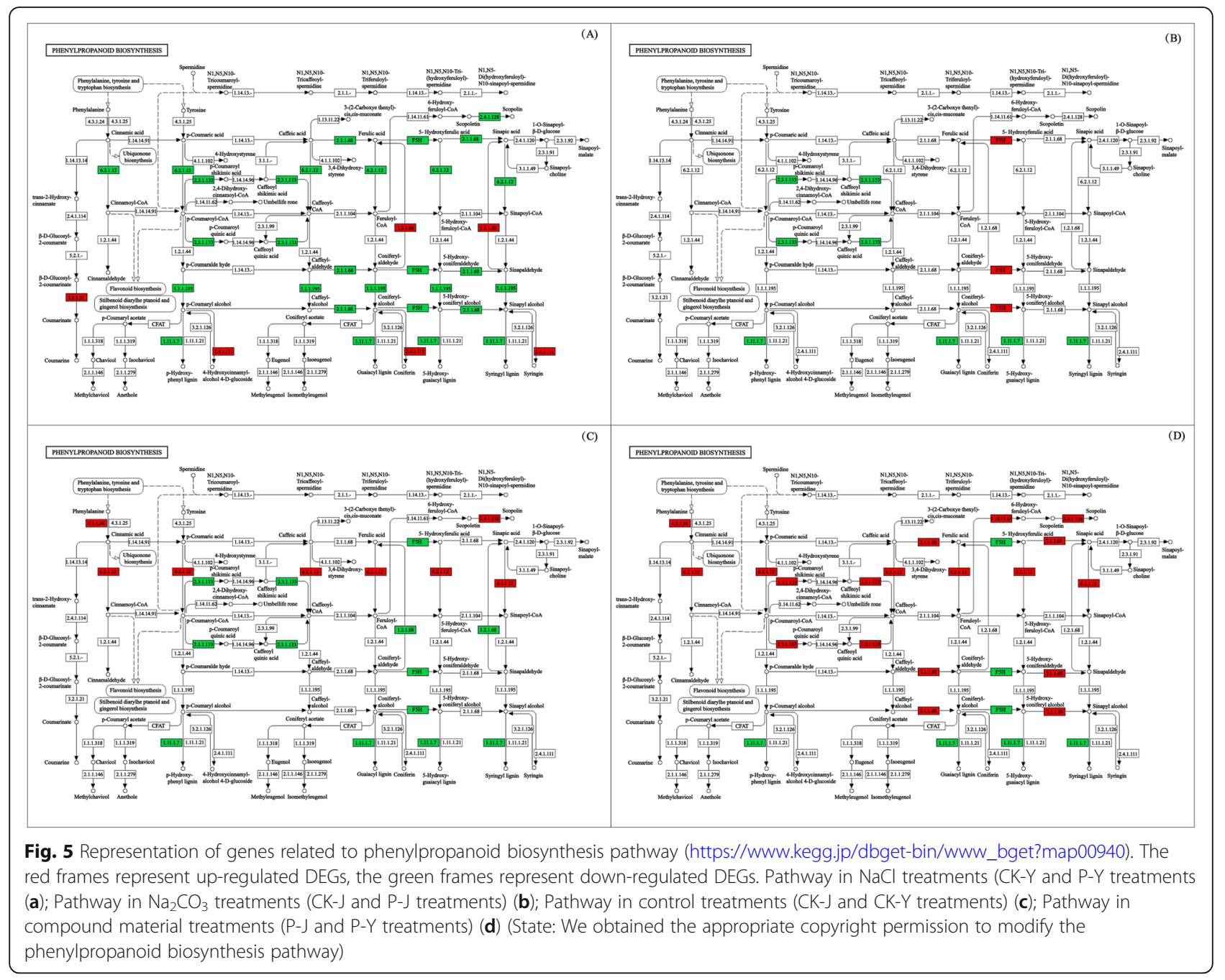

experiments. In this study, the $\mathrm{Na}^{+}$and $\mathrm{K}^{+}$contents of cotton leaves under alkaline stress were significantly higher than those under saline stress, and there was no significant difference in $\mathrm{K}^{+} / \mathrm{Na}^{+}$ratio. In order to regulate the responses of cotton to saline stress and alkaline stress, the compound material was applied in field experiments. Zhang, et al. [23] found that the $\mathrm{Na}^{+} / \mathrm{H}^{+}$exchanger 4 of sesame aerial parts was up-regulated under saline stress through hydroponic culture. Zhao, et al. [24] found $17 \mathrm{Na}^{+} / \mathrm{H}^{+}$antiporters in the root of chrysanthemum in response to saline stress. Niu, et al. [25] found that salinity significantly decreased the expression of $\mathrm{Na}^{+} / \mathrm{H}^{+}$exchanger 4 in leaf veins. In the study, for compound material treatments, the $\mathrm{Na}^{+}$content was decreased; this might be because the stress signal of $\mathrm{Na}^{+}$ could be quickly inhibited by the down-regulation of a $\mathrm{Na}^{+} / \mathrm{H}^{+}$exchanger 3 gene when the compound material was applied to salinized soil. Moreover, $\mathrm{Na}^{+} / \mathrm{H}^{+}$exchangers reduced the accumulation of $\mathrm{Na}^{+}$by fixing $\mathrm{Na}^{+}$ and storing it in vacuoles [26, 27]. Huang, et al. [28] found that the potassium channel KAT1 of the aboveground part of barley was down-regulated under saline stress. In this study, under saline stress and alkaline stress, the $\mathrm{K}^{+}$content and $\mathrm{K}^{+} / \mathrm{Na}^{+}$ratio for compound material treatments were increased; this might be because the application of compound material increased the transcription level of certain genes encoding $\mathrm{K}$ transporters and $\mathrm{K}$ channels in cotton leaves. In particular, under saline stress, several genes of two-pore $\mathrm{K}^{+}$channel 1 and $\mathrm{K}^{+}$transporter 1 for saline treatments were upregulated, and several genes of $\mathrm{K}^{+}$transporter 2 and two-pore $\mathrm{K}^{+}$channel 1 for alkaline treatments were also up-regulated. Among them, the up-regulation of $\mathrm{GH}_{-}$ A13G1568, GH_D01G0882, GH_D13G1517, GH A01G0868, and GH_D05G2808 genes had positive effects on $\mathrm{K}^{+} / \mathrm{Na}^{+}$ratio, which suggested that the compound material could alleviate saline stress and alkaline stress by regulating ion balance in leaves. Moreover, a $\mathrm{K}^{+}$channel SKOR gene was down-regulated for the $\mathrm{Na}_{2} \mathrm{CO}_{3}$ treatments compared with that for the $\mathrm{NaCl}$ 
treatments, suggesting that the application of the compound material had a better effect on the recovery of $\mathrm{K}^{+}$ content of cottons under saline stress.

The differences in $\mathrm{K}^{+}$and $\mathrm{Na}^{+}$contents between $\mathrm{NaCl}$ treatments and $\mathrm{Na}_{2} \mathrm{CO}_{3}$ treatments were due to the different physiological damages suffered by cotton. In this study, it was found that alkaline stress caused more physiological damage to cotton leaves than saline stress. Gong, et al. [12] found that the application of exogenous substances could promote the antioxidant system to remove excess free radicals and regulate physiological damage. In this study, we also found that the application of the compound material could regulate the physiological damage suffered by cotton. It had the same effect on the regulation of antioxidant enzymes under saline stress and alkaline stress, but the degrees of the effects were different. For example, no matter under saline stress or under alkaline stress, the compound material could increase the SOD, POD, and CAT activities of cotton leaves. This might be because a large number of DEGs were related to oxidoreductase activity for CK-Y, P-Y, CK-J, and P-J treatments. A total of 51 DEGs of oxidoreductase activity Go term for $\mathrm{NaCl}$ treatments were regulated, and 29 DEGs for $\mathrm{Na}_{2} \mathrm{CO}_{3}$ treatments were regulated; moreover, the compound material activated the oxidative stress response under saline stress and alkaline stress. Among them, the compound material significantly increased the activities of SOD and CAT under saline stress. This might be because the upregulation of GH_A06G1119, GH_A12G2651, GH_ D06G1268, and GH_A06G1247 increased SOD activity, while the up-regulation of GH_D10G1060 increased CAT activity; however, the compound material did not significantly increase the activities of SOD and CAT under alkaline stress, indicating that the compound material had less effect on the activities of SOD and CAT under alkaline stress, and SOD activity might not play a role in saline and alkaline tolerances of cotton [29]. Studies have shown that POD is the main detoxification enzyme of plants under saline stress and alkaline stress [30]. This study found that the compound material significantly increased the POD activity of cotton leaves under saline stress and alkaline stress. This might be because the genes related to peroxidase for CK-Y, P-Y, CK-J, and P-J treatments were up-regulated, and the expression of antioxidant enzyme genes was also upregulated, leading to the improvement of the tolerance of cotton to saline stress and alkaline stress after applying the compound material; besides, the application of compound material under saline stress up-regulated, the expression of a great number of antioxidant enzyme genes. Luo, et al. [31] showed that SOD1 and CAT1 genes were involved in the cottons' response to saline stress. Geng, et al. [32] found that the POD7 and SOD
$[\mathrm{Cu}-\mathrm{Zn}]$ genes of the salt-tolerant varieties of sugar beet were significantly up-regulated. However, in our study, the application of compound material only significantly regulated the POD A2/50/5/46/29/12/P7 in cotton leaves. This might be because the permeability of the soil in the field enhanced root vitality and promoted cotton's tolerance, so only peroxidase-related genes were involved in the responses to saline stress and alkaline stress. We also noticed that under saline stress and alkaline stress, the REC and MDA in leaves were affected. The difference in REC under saline stress and alkaline stress was not significant, but the MDA content under alkaline stress was much higher than that under saline stress. Cui, et al. [33] found that the RCE of peanut leaves was increased under saline stress. Gong, et al. [12] found that the leaf MDA content of Malus hupehensis Rehd. under alkaline stress was decreased by applying melatonin. Our study found that the application of the compound material to cottons under saline stress and alkaline stress increased the REC content of cotton leaves. Among them, only the increase in REC of cottons under saline stress was significant. This might be because the up-regulation of GH_A06G1119, GH_D10G1060, GH_ A12G2651, and GH_D10G1977 increased the REC content, indicating that the compound material decreased the effects of saline stress and alkaline stress on the stability and integrity of the cell membrane. Moreover, the effect of the compound material on the cell membrane of cottons under saline stress was more significant than that under alkaline stress.

The genes for lignin biosynthesis are dynamically regulated at different levels to protect plant cell metabolism from oxidative damage [34]. In the transcription of data, functional analysis of DEGs was performed through KEGG and GO enrichment analysis, and it was found that a large number of genes were involved in the phenylpropanoid biosynthesis pathway. The phenylpropanoid biosynthesis pathway is one of the most important secondary metabolite pathways in plants, and is related to the plant's response to saline stress and alkaline stress [35]. The lignin metabolites produced in this pathway are of great significance for plants to resist abiotic stress $[35,36]$. Besides, four lignins (p-hydroxyphenyl lignin, guaiacyl lignin, 5-hydroxy-guaiacyl lignin, and syringyl lignin) were aggregated by four monomers (p-coumaryl alcohol, coniferyl alcohol, 5-hydroxy-coniferyl alcohol, and sinapyl alcohol), while four alcohols were catalyzed by peroxidase (EC: 1.11.1.7), leading to the formation of these lignins (Fig. 5). Shen, et al. [37] found that seven genes related to lignin biosynthesis in Arabidopsis thaliana were up-regulated under saline stress. We found that 4CL, HCT, COMT, TOGT1, F5H, CAD, and POD enzymes for the P-Y treatment were down-regulated compared with those for the CK-Y treatment, suggesting 
that these enzymes might play a role in the decrease of lignin synthesis and the protection of cotton from the damage caused by saline stress by compound material. Moreover, previous studies have found that 4CL enzyme changes the accumulation of lignin [38], HCT enzyme modifies $\mathrm{H}$ lignin (p-hydroxyphenyl lignin) [39], COMT enzyme participates in the biosynthesis of S lignin (syringyl lignin) [40], F5H enzyme regulates the composition of S/G lignin (syringyl (S)/ guaiacyl (G) lignin) [41], CAD enzymes change the lignin content and structure [42], and POD enzymes participate in lignin biosynthesis and affect plant growth [43]. In this study, the expression levels of HCT and POD enzymes for the P-J treatment were down-regulated compared with those for the CK-J treatment, suggesting that 5-OCaffeoylshikimic acid and caffeoyl quinic acid could not be converted into caffeoyl-CoA. However, caffeoyl-CoA is an essential intermediate for lignin biosynthesis [44]. The above indicates that under both saline stress and alkaline stress, the application of compound material downregulates the peroxidase (EC: 1.11.1.7), which might be because the compound material reduces the lignin biosynthesis under saline stress and alkaline stress.

\section{Conclusions}

Field test results showed that saline stress and alkaline stress were two different stresses. Under saline stress, the contents of $\mathrm{Na}^{+}$and MDA in cotton leaves were high, the activities of POD and CAT were low, and the effect of alkaline stress were greater than that of saline stress. The application of the compound material was mainly to increase cotton $\mathrm{K}^{+} / \mathrm{Na}^{+}$ratio and POD activity to increase saline and alkaline tolerance of cotton. Through transcriptome analysis, it was further found that $\mathrm{K}^{+}$transporter genes and peroxidase-related genes were up-regulated during the regulation of the responses of cotton to saline stress and alkaline stress by the compound material; and the enzymes involved in lignin biosynthesis were down-regulated, which protected cotton from the damage caused by saline stress and alkaline stress (Fig. 6). Among them, these up-regulated genes and down-regulated enzymes were abundant in cotton leaves during the regulation of the responses of cotton to saline stress by compound material. Moreover, these differentially expressed genes obtained in field trials have high stability, which is applicable in the field breeding in the future.

\section{Methods}

\section{Experiment site}

Cotton (Xinluzao 62) seeds were obtained from Cotton Crops Research Institute (Shihezi City, Xinjiang, China). This experiment was conducted at the Experimental Station of Grape Research Institute in Shihezi City, Xinjiang Province, China $\left(44^{\circ} 20^{\prime} \mathrm{N} 、 86^{\circ} 03^{\prime} \mathrm{E}\right)$. The soil is a desert grey soil. Soil basic characteristics are shown in Table 3.

\section{Experimental materials and experimental design}

This experiment was conducted from April 20th to September 20th, 2018. The cotton (variety Xinluzao 62)
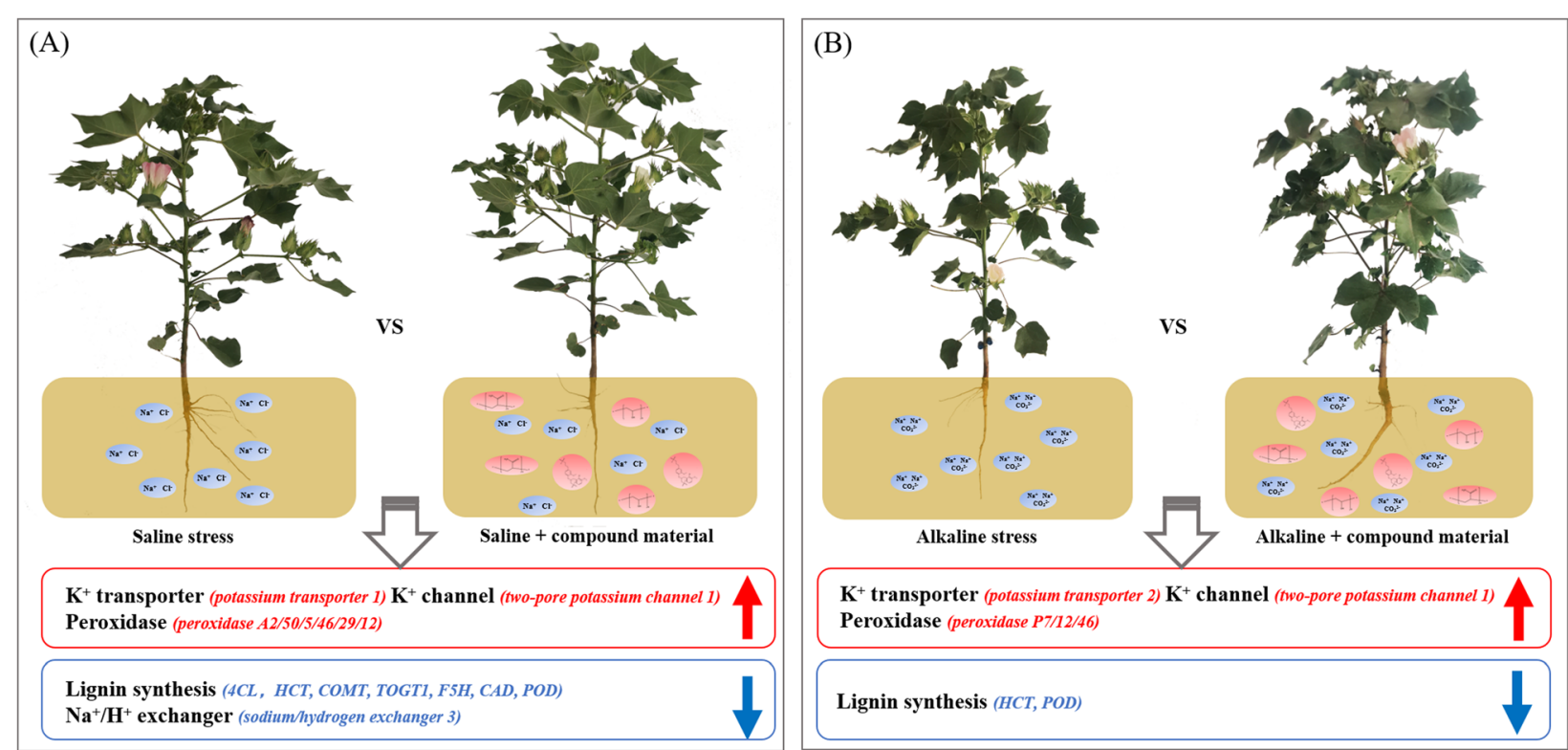

Fig. 6 Proposed model for the function of compound material in regulating saline stress (a) and alkaline stress (b) of cotton leaves. The uppointing red arrows mean that the candidate genes are up-regulated; the down-pointing blue arrows mean that the candidate genes are down-regulated 
Table 3 Soil basic characteristics of the tested soil [45]

\begin{tabular}{ll}
\hline Item & Value \\
\hline $\mathrm{pH}$ & 7.72 \\
cation exchange capacity (CEC) & $17.32 \mathrm{coml} \mathrm{kg}^{-1}$ \\
Organic matter contents & $12.5 \mathrm{~g} \mathrm{~kg}^{-1}$ \\
Alkali-hydrolyzable nitrogen & $54 \mathrm{mg} \mathrm{kg}^{-1}$ \\
Available phosphorus & $11.7 \mathrm{mg} \mathrm{kg}^{-1}$ \\
Available potassium & $218 \mathrm{mg} \mathrm{kg}^{-1}$ \\
\hline
\end{tabular}

and a compound material were used as the experimental material in this study. Compound material was a mixture of calcium lignosulfonate, manganese sulfate, zinc sulfate, ferric sulfate, and boric acid, anionic polyacrylamide, polyvinyl alcohol (Mass ratio: 4:4:4:2: 1:0.5:0.5).

This experiment employed a randomized block design. There were four treatments in total and each treatment had three repetitions: (1) P-Y treatment (compound material of $300 \mathrm{~kg} \mathrm{hm}^{-2}$ was applied and $\mathrm{NaCl}$ of $8 \mathrm{~g} \mathrm{~kg}^{-1}$ was mixed fully with the plough layer), (2) P-J treatment (compound material of $300 \mathrm{~kg} \mathrm{hm}^{-2}$ was applied and $\mathrm{Na}_{2} \mathrm{CO}_{3}$ of $8 \mathrm{~g} \mathrm{~kg}^{-1}$ was mixed fully with the plough layer), (3) $\mathrm{CK}-\mathrm{Y}$ treatment (no compound material was applied and $\mathrm{NaCl}$ of $8 \mathrm{~g} \mathrm{~kg}^{-1}$ was mixed fully with the plough layer), and (4) CK-J treatment (no compound material was applied and $\mathrm{Na}_{2} \mathrm{CO}_{3}$ of $8 \mathrm{~g} \mathrm{~kg}^{-1}$ was mixed fully with the plough layer). On April 20th, 2018, soils were put into plastic barrels $(0.5 \mathrm{~m}$ in diameter and 0.6 $\mathrm{m}$ in height) keeping the status of soil layer, and then barrels were buried back to the field. After that, $\mathrm{NaCl}$ and $\mathrm{Na}_{2} \mathrm{CO}_{3}$ were applied. The $\mathrm{pH}$ and $\mathrm{EC}$ of salinized soil were 8.24 and $1.84 \mathrm{~s} \mathrm{~m}^{-1}$, respectively, and those of alkalized soil were 9.78 and $1.03 \mathrm{~s} \mathrm{~m}^{-1}$, respectively. On April 29th, for all treatments, $0.2 \mathrm{~g} \mathrm{~kg}^{-2}$ urea and $0.4 \mathrm{~g}$ $\mathrm{kg}^{-2}$ synthetic fertilizer (formulated for drip irrigation; $\mathrm{N}: 0.07 \mathrm{~g} \mathrm{~kg}^{-2}$; P: $0.07 \mathrm{~g} \mathrm{~kg}^{-2}$; K: $0.07 \mathrm{~g} \mathrm{~kg}^{-2}$ ) were applied. On May 4th, cotton was sown; and after emergence, six seedlings were retained in each barrel. On May 6th, the compound material was applied after diluting with water. Both the fertilizer and compound material were applied to soils with drip irrigation at once. The seedlings were irrigated for the first time on June 25th. The irrigation cycle was 3 days. At the flowering and boll-forming stage (August 19th), new leaves were collected for transcriptome sequencing (three replicates per treatment). All samples were immediately placed in liquid nitrogen and stored at $-80^{\circ} \mathrm{C}$ until use.

\section{Plant physiological analysis}

The activities of antioxidant enzymes were assayed in leaves $(0.5 \mathrm{~g})$ using spectrophotometric methods [4648]. Superoxide dismutase (SOD) activity was measured $(560 \mathrm{~nm})$ based on the NBT photochemical reduction
[46]. The peroxidase (POD) activity was measured (470 $\mathrm{nm}$ ) based on the absorbance caused by guaiacol [47]. The catalase (CAT) activity was measured $(240 \mathrm{~nm})$ based on the reaction of potassium phosphate buffer and $\mathrm{H}_{2} \mathrm{O}_{2}$ [48].

Malondialdehyde (MDA) was measured in terms of a thiobarbituric acid reactive substances (TBARS) content of the leaf samples (nmol/g; extinction coefficient: $155 \mathrm{mM} \mathrm{cm}^{-1}$ ) [49]. For relative electrical conductivity (REC) [50], $0.1 \mathrm{~g}$ of fresh leaves were cut into $1 \mathrm{~cm}$ slices, placed in $10 \mathrm{~mL}$ of deionized water, and shaken for $24 \mathrm{~h}$ at room temperature on a rotary shaker (QL200H, Shanghai, China). Then, electrical conductivity of the solution (L1) was measured using a conductivity meter (EM38, ICT international, Armidale, NSW, Australia). The solution was boiled for $15 \mathrm{~min}$ and cooled to room temperature, and electrical conductivity (L2) was again measured. Finally, REC was calculated (REC $=\mathrm{L} 1 / \mathrm{L} 2)$.

The $\mathrm{Na}^{+}$and $\mathrm{K}^{+}$contents of the leaf samples were determined according to the method of Bao [45]. Leaf samples were immersed in $98 \% \mathrm{H}_{2} \mathrm{SO}_{4}$ and $30 \% \mathrm{H}_{2} \mathrm{O}_{2}$, and a flame spectrophotometer (AP1200 type, Shanghai, China) was used for the determination.

\section{Transcriptome sequencing and data analysis}

In this study, total RNA of 12 samples was extracted [51], PolyA mRNA in total RNA was enriched by Oligo (dT) magnetic beads, and RNA was interrupted about $300 \mathrm{bp}$ in length by ion interruption. The first strand of cDNA was synthesized using 6 base random primers and reverse transcriptase as template, and the second strand cDNA was synthesized using the first strand cDNA as template. After the construction of the library, the library fragments were enriched by PCR amplification, and then the library was selected according to the size of the fragments (450 bp). Then, Agilent 2100 Bioanalyzer (Agilent Technologies, Palo Alto, Calif.) was used to check the total concentration and effective concentration of the library. Then, according to the effective concentration of the library and the amount of data needed by the library, the libraries containing different Index sequences are mixed proportionally. After RNA extraction, purification and library construction, these samples were sequenced by Next-Generation Sequencing (NGS) based on Illumina Sequencing platform [51]. The RNA library construction was carried out by Shanghai Personal Bioinformatics Co., Ltd. (http://www.personalbio.cn/).

The quality of the reads was checked using FastQC (http://www.bioinformatics.babraham.ac.uk/projects/fastqc/). Fastp was used to remove the adapter and low-quality sequences in the reads [52]. Cotton genome sequence of (Gossypium hirsutum, ZJU) were downloaded from 
$\mathrm{Hu}$, et al. [53] and used as the reference genome (https://www.cottongen.org/species/Gossypium_hirsutum/ ZJU-AD1_v2.1). The clean reads were qausi-mapped on to all annotated transcripts using Salmon [54]. Expression abundance at the unit of transcript per million (TPM) was calculated at gene level. DESeq2 was used to identify the differentially expressed genes (DEGs) between samples with the thresholds of adjusted $p$-value less than 1 and absolute value of $\log 2$ (fold change) larger than 1 [55]. Principal component analysis (PCA) was performed to display the transcriptomic similarity among the samples based on the counts of top 1000 genes. Gene ontology (GO) and Kyoto Encyclopedia of Genes and Genomes (KEGG) enrichment analyses were conducted using clusterProfiler [56]. Pathway analysis done using the KEGG mapping method. The Unigene sequences were mapped to the KEGG biochemical pathways according to the EC distribution in the pathway database $[57,58]$.

\section{Quantitative real-time PCR validation}

To validate the RNA-seq data, six DEGs from the pathway enrichment analysis were selected for qRTPCR analysis. Samples of RNA-Seq were reverse transcribed into cDNA for real-time qPCR validation using the PrimeScript ${ }^{\mathrm{Tm}}$ 1st stand cDNA Synthesis Kit and SYBR Green Master Mixes (Vazyme Biotech, Nanjing, China). qRT-PCR was performed on a fluorescence quantitative system TIB8600 (Taipu, Biotech, Xiamen, China). Each sample was measured with three biological and three technical replicates, and the relative expression levels were calculated using the $2^{-\Delta \Delta \mathrm{Ct}}$ method. The endogenous reference gene used was GhEF1 $\alpha$. The gene-specific primers are listed in Table S2 (Additional file 1).

\section{Statistical analysis}

One-way analysis of variance (ANOVA) was performed for $\mathrm{K}^{+}$and $\mathrm{Na}^{+}$contents and physiological characteristics of cotton leaves (Duncan test, $P<0.05$, SPSS 22.0). All the above analyses were performed in $\mathrm{R}$ software (Version 3.2.3, http://www.r-project.org) using the Vegan and Origin 8.0 software.

\section{Supplementary information}

Supplementary information accompanies this paper at https://doi.org/10. 1186/s12870-020-02649-0.

Additional file 1: Table S1. Statistical analyses and mapping results of RNA sequencing reads. Table S2. Primers used in qRT-PCR analysis.

Additional file 2: Figure S1. An overview of RNA-Seq data

Additional file 3: Figure S2. PCA clustering based on RNA-Seq data

Additional file 4: Figure S3. Correlation analysis between $q R T-P C R$ and RNA-Seq data based on log2 fold change
Additional file 5: Figure S4. KEGG enrichment analysis of DEGs. (A) Pathways in $\mathrm{NaCl}$ treatments (CK-Y and $P-Y$ treatments). (B) Pathways in $\mathrm{Na}_{2} \mathrm{CO}_{3}$ treatments (CK-J and P-J treatments). (C) Pathways in the controls (CK-J and CK-Y treatments). (D) Pathways in compound material treatments ( $\mathrm{P}-\mathrm{J}$ and $\mathrm{P}-\mathrm{Y}$ treatments).

\section{Abbreviations}

SOD: Superoxide dismutase; POD: Peroxidase; CAT: Catalase; MDA: Malondialdehyde; REC: Relative electrical conductivity; Go: Gene ontology; KEGG: Kyoto Encyclopedia of Genes and Genomes; DEGs: Differentially expressed genes (DEGs)

\section{Acknowledgements}

Not applicable.

\section{Authors' contributions}

MJA, XLW, and KYW conceived and designed the experiments; MJA and XLW performed experiment and analyzed data; DDC, SW, and DSH assisted with the experiments; MJA wrote the manuscript; KYW and HF revised the manuscript. All authors read and approved the manuscript.

\section{Funding}

The research was supported by the National Key Research and Development Program of China (2016YFC0501406); Major Science and Technology Project of Xinjiang Production and Construction Corps (2018AA005), and Program of Shihezi University (GJHZ201802). The funders had no role in the experimental design, data collection and analysis or writing the manuscript.

Availability of data and materials

The raw RNA-seq data are available from NCBI Sequence Read Archive (SRA) database under accession PRJNA660498 (https://www.ncbi.nlm.nih.gov/sra/ PRJNA660498). All data generated or analyzed during this study are available from the corresponding author on reasonable request.

Ethics approval and consent to participate

Not applicable.

Consent for publication

Not applicable.

\section{Competing interests}

The authors declare that they have no competing interests.

Received: 23 May 2020 Accepted: 14 September 2020

Published online: 08 October 2020

References

1. Li YY, Zhao K, Ren JH, Ding LY, Wu LL. Analysis of the dielectric constant of saline-alkali soils and the effect on radar backscattering coefficient: a case study of soda alkaline saline soils in western Jilin Province using RADARSAT2 data. Sci World J. 2014;56:30-45.

2. Ge Y, Li Y, Lv DK, Bai X, Ji W, Cai H, Wang AX, Zhu YM. Alkaline-stress response in Glycine soja leaf identifies specific transcription factors and ABA-mediated signaling factors. Funct Integr Genomic. 2011;11:369-79.

3. Wang G, Zhu QG, Meng QW, Wu CA. Transcript profiling during salt stress of young cotton (Gossypium hirsutum) seedlings via solexa sequencing. Acta Physiol Plant. 2012;34(1):107-15.

4. Li Q, Yang A, Zhang WH. Comparative studies on tolerance of rice genotypes differing in their tolerance to moderate salt stress. BMC Plant Biol. 2017;17(1):141.

5. Munns R, Tester M. Mechanisms of salinity tolerance. Annu Rev Plant Biol. 2008;59:651-81.

6. Guo HJ, Hu ZQ, Zhang HM, Min W, Hou ZA. Comparative effects of salt and alkali stress on antioxidant system in cotton (Gossypium hirsutum L.) leaves. Open Chem. 2019;17(1):1352-60.

7. Jia XM, Wang H, Svetla S, Zhu YF, Hu Y, Cheng L, Zhao T, Wang YX. Comparative physiological responses and adaptive strategies of apple Malus halliana to salt, alkali and saline-alkali stress. Sci Hortic. 2019;245:154-62. 
8. Ma HX, Meng CM, Zhang KX, Wang KY, Fan H, Li YB. Study on physiological mechanism of using cottonseed meal to improve salt-alkali tolerance of cotton. J Plant Growth Regul. 2020:1-11.

9. Wang XP, Geng SJ, Ri YJ, Cao DH, Liu J, Shi DC, Yang CW. Physiological responses and adaptive strategies of tomato plants to salt and alkali stresses. Sci Hortic. 2011;130(1):248-55.

10. Kiełkowska A, Grzebelus E, Lis-Krzyścin A, Maćkowska K. Application of the salt stress to the protoplast cultures of the carrot (Daucus carota L.) and evaluation of the response of regenerants to soil salinity. Plant Cell Tissue Org. 2019;137:379-95.

11. Mao L, Lu JG, Jiang HY. Mechanisms of plant responses to salt-alkali stress. Mol Plant Breed. 2019;1:07-24.

12. Gong XQ, Shi ST, Dou F, Ma FW. Exogenous melatonin alleviates alkaline stress in malus hupehensis rehd by regulating the biosynthesis of polyamines. Molecules. 2017;22(9):1542.

13. Faghih S, Zarei A, Ghobadi C. Positive effects of plant growth regulators on physiology responses of fragaria $\times$ ananassa $\mathrm{cv}$. 'camarosa' under salt stress. Int J Fruit Sci. 2018;19(2):104-14.

14. Ashraf J, Zuo DY, Wang DY, Malik W, Zhang YP, Abid MA, Cheng HL, Yang $\mathrm{QH}$, Song GL. Recent insights into cotton functional genomics: progress and future perspectives. Plant Biotechnol J. 2018;16(3):699-713.

15. Yin ZP, Zhang H, Zhao Q, Yoo MJ, Zhu N, Yu JL, Yu JJ, Guo SY, Miao YC, Chen SX, et al. Physiological and comparative proteomic analyses of salinealkali $\mathrm{NaHCO}_{3}$-responses in leaves of halophyte Puccinellia tenuiflora. Plant Soil. 2019;437(1-2):137-58.

16. Razzaq A, Ali A, Safdar LB, Zafar MM, Rui Y, Shakeel A, Shaukat A, Ashraf M, Gong WK, Yuan YL. Salt stress induces physiochemical alterations in rice grain composition and quality. J Food Sci. 2020;85(1):14-20.

17. Wei YY, Xu YC, Lu P, Wang XX, Li ZQ, Cai XY, Zhou ZL, Wang YH, Zhang ZM, Lin ZX, et al. Salt stress responsiveness of a wild cotton species (Gossypium klotzschianum) based on transcriptomic analysis. PLoS One. 2017;12(5): e0178313.

18. Chen L, Liu LT, Lu B, Ma TT, Jiang D, Li J, Zhang K, Sun HC, Zhang YJ, Bai ZY, et al. Exogenous melatonin promotes seed germination and osmotic regulation under salt stress in cotton (Gossypium hirsutum L.). PLoS One. 2020;15(1):e0228241.

19. Guo HJ, Li SN, Min W, Ye J, Hou ZA. lonomic and transcriptomic analyses of two cotton cultivars (Gossypium hirsutum L.) provide insights into the ion balance mechanism of cotton under salt stress. PLoS One. 2019;14(12):e0226776.

20. Xu YC, Magwanga RO, Yang $X$, Jin DS, Cai XY, Hou YQ, Wei YY, Zhou ZL, Wang KB, Liu F. Genetic regulatory networks for salt-alkali stress in Gossypium hirsutum with differing morphological characteristics. BMC Genomics. 2020;21(1):1-15.

21. Lee SB, Kwon HB, Kwon SJ, Park SC, Jeong MJ, Han SE, Byun MO, Daniell H. Accumulation of trehalose within transgenic chloroplasts confers drought tolerance. Mol Breed. 2003;11:1-13.

22. Zhu JK. Abiotic stress signaling and responses in plants. Cell. 2016;167(2): 313-24.

23. Zhang YJ, Li DH, Zhou R, Wang X, Dossa K, Wang LH, Zhang YX, Yu JY, Gong HH, Zhang XR, et al. Transcriptome and metabolome analyses of two contrasting sesame genotypes reveal the crucial biological pathways involved in rapid adaptive response to salt stress. BMC Plant Biol. 2019;19(1): 66-79.

24. Zhao Q, He L, Wang B, Liu QL, Pan YZ, Zhang F, Jiang BB, Zhang L, Liu GL, Jia $Y$. Transcriptome comparative analysis of salt stress responsiveness in chrysanthemum (Dendranthema grandiflorum) roots by illumina- and singlemolecule real-time-based RNA sequencing. DNA Cell Biol. 2018;37(12):1-15.

25. Niu ML, Xie JJ, Chen C, Cao HS, Sun JY, Kong QS, Shabala S, Shabala L, Huang Y, Bie ZL. An early aba-induced stomatal closure, $\mathrm{Na}^{+}$sequestration in leaf vein and $\mathrm{K}^{+}$retention in mesophyll confer salt tissue tolerance in cucurbita species. J Exp Bot. 2018;69(20):4945-60.

26. Barragán V, Leidi EO, Andrés Z, Rubio L, Luca AD, Fernández JA, Cubero B, Pardo JM. Ion exchangers NHX1 and NHX2 mediate active potassium uptake into vacuoles to regulate cell turgor and stomatal function in Arabidopsis. Plant Cell. 2012;24:1127-42.

27. Qiu QS, Guo Y, Quintero FJ, Pardo JM, Schumaker KS, Zhu JK. Regulation of vacuolar $\mathrm{Na}^{+} / \mathrm{H}^{+}$exchange in Arabidopsis thaliana by the salt-overlysensitive (SOS) pathway. J Biol Chem. 2004;279:207-15.

28. Huang L, Kuang LH, Li X, Wu LY, Wu DZ, Zhang GP. Metabolomic and transcriptomic analyses reveal the reasons why Hordeum marinum has higher salt tolerance than Hordeum vulgare. Environ Exp Bot. 2018;156:48-61.
29. Chakraborty K, Bishi SK, Goswami N, Singh AL, Zala PV. Differential fineregulation of enzyme driven ROS detoxification network imparts salt tolerance in contrasting peanut genotypes. Environ Exp Bot. 2016;128:79-90.

30. Zhang L, Ma HJ, Chen TT, Pen J, Yu SX, Zhao XH. Morphological and physiological responses of cotton (Gossypium hirsutum L.) plants to salinity. PLoS One. 2014;9(11):e112807.

31. Luo XL, Wu JH, Li YB, Nan ZR, Guo X, Wang YX, Zhang AH, Wang ZA, Xia GX, Tian YC. Synergistic effects of GhSOD1 and GhCAT1 overexpression in cotton chloroplasts on enhancing tolerance to methyl viologen and salt stresses. PLoS One. 2013;8(1):e54002.

32. Geng G, Lv C, Stevanato P, Li R, Liu H, Yu L, Wang Y. Transcriptome analysis of salt-sensitive and tolerant genotypes reveals salt-tolerance metabolic pathways in sugar beet. Int J Mol Sci. 2019;20(23):E5910.

33. Cui F, Sui N, Duan GY, Liu YY, Han Y, Liu SS, Wan SB, Li GW. Identification of metabolites and transcripts involved in salt stress and recovery in peanut. Front Plant Sci. 2018;9:217

34. Shafi A, Chauhan R, Gill T, Swarnkar MK, Sreenivasulu Y, Kumar S, Kumar N, Shankar R, Ahuja PS, Singh AK. Expression of SOD and APX genes positively regulates secondary cell wall biosynthesis and promotes plant growth and yield in Arabidopsis under salt stress. Plant Mol Biol. 2015:87(6):615-31.

35. Chun HJ, Baek D, Cho HM, Lee SH, Jin BJ, Yun DJ. Lignin biosynthesis genes play critical roles in the adaptation of Arabidopsis plants to high-salt stress. Plant Signal Behav. 2019;14(8):1625697.

36. Dixon RA, Liu CG, Jun JH. Metabolic engineering of anthocyanins and condensed tannins in plants. Curr Opin Biotechnol. 2013;24(2):329-35.

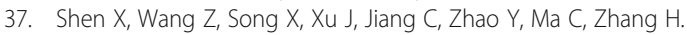
Transcriptomic profiling revealed an important role of cell wall remodeling and ethylene signaling pathway during salt acclimation inarabidopsis. Plant Mol Biol. 2014;86(3):303-17.

38. Liu H, Guo ZH, Gu FW, Ke SW, Sun DY, Dong SY, Liu W, Huang M, Xiao WM, Yang $\mathrm{GL}$, et al. 4-Coumarate-CoA ligase-like gene OsAAE3 negatively mediates the rice blast resistance, floret development and lignin biosynthesis. Front Plant Sci. 2017;7:2041.

39. Vanholme B, Cesarino I, Goeminne G, Kim H, Marroni F, Van Acker R, Vanholme R, Morreel K, Ivens B, Pinosio S, et al. Breeding with rare defective alleles (BRDA): a natural populus nigra HCT mutant with modified lignin as a case study. New Phytol. 2013;198(3):765-76.

40. Eudes A, Dutta T, Deng K, Jacquet N, Sinha A, Benites VT, Baidoo EEK, Richel A, Sattler SE, Northen TR, et al. SbCOMT (Bmr12) is involved in the biosynthesis of tricin-lignin in sorghum. PLoS One. 2017;12(6):e0178160.

41. Wagner A, Tobimatsu Y, Phillips L, Flint H, Geddes B, Lu F, Ralph J. Syringyl lignin production in conifers: proof of concept in a pine tracheary element system. Proc Natl Acad Sci. 2015;112(19):6218-23.

42. Van Acker R, Déjardin A, Desmet S, Hoengenaert L, Vanholme R, Morreel K, Laurans F, Kim H, Santoro N, Foster C, et al. Different routes for conifer- and sinapaldehyde and higher saccharification upon deficiency in the dehydrogenase CAD1. Plant Physiol. 2017;175(3):1018-39.

43. Herrero J, Fernández-Pérez F, Yebra T, Novo-Uzal E, Pomar F, Pedreño MÁ, Cuello J, Guéra A, Esteban-Carrasco A, Zapata JM. Bioinformatic and functional characterization of the basic peroxidase 72 from Arabidopsis thaliana involved in lignin biosynthesis. Planta. 2013;237(6):1599-612.

44. Liu QQ, Luo L, Zheng LQ. Lignins: biosynthesis and biological functions in plants. Int J Mol Sci. 2018;19(2):335.

45. Bao SD. Soil agrochemical analysis. 3rd ed. Beijing: China Agriculture Press; 2000.

46. Paoletti F, Aldinucci D, Mocali A, Caparrini A. A sensitive spectrophotometric method for the determination of superoxide dismutase activity in tissue extracts. Anal Biochem. 1986;154(2):536-41.

47. Zhou W, Leul M. Uniconazole-induced tolerance of rape plants to heat stress in relation to changes in hormonal levels, enzyme activities and lipid peroxidation. Plant Growth Regul. 1999;27(2):99-104.

48. Cakmak I, Marschner H. Magnesium deficiency and high light intensity enhance activities of superoxide dismutase, ascorbate peroxidase, and glutathione reductase in bean leaves. Plant Physiol. 1992;98(4):1222-7.

49. Heath RL, Packer L. Photoperoxidation in isolated chloroplasts: I. kinetics and stoichiometry of fatty acid peroxidation. Arch Biochem Biophys. 1968;125(1): 189-98.

50. Lutts S, Kinet JM, Bouharmont J. NaCl-induced senescence in leaves of rice (Oryza satival.) cultivars differing in salinity resistance. Ann Bot-London. 1996;78(3):389-98 
51. Ma W, Li X, Shen J, Du Y, Xu K, Jiang Y. Transcriptomic analysis reveals Apis mellifera adaptations to high temperature and high humidity. Ecotoxicol Environ Saf. 2019;184:109599.

52. Chen SF, Zhou YQ, Chen YR, Gu J. Fastp: an ultra-fast all-in-one FASTQ preprocessor. Bioinformatics. 2018;34(17):884-90.

53. Hu Y, Chen J, Fang L, Zhang Z, Ma W, Niu Y, Ju L, Deng J, Zhao T, Lian J. Gossypium barbadense and Gossypium hirsutum genomes provide insights into the origin and evolution of allotetraploid cotton. Nat Genet. 2019;51(4): 739-48.

54. Patro R, Duggal G, Love Ml, Irizarry RA, Kingsford C. Salmon provides fast and bias-aware quantification of transcript expression. Nat Methods. 2017; 14(4):417-9.

55. Love MI, Huber W, Anders S. Moderated estimation of fold change and dispersion for RNA-seq data with DESeq2. Genome Biol. 2014;15(12):550.

56. Yu G, Wang LG, Han Y, He QY. Clusterprofiler: an R package for comparing biological themes among gene clusters. OMICS. 2012;16(5):284-7.

57. Kanehisa M, Goto S. KEGG: Kyoto encyclopedia of genes and genomes. Nucleic Acids Res. 2000;28:27-30

58. Moriya Y, Itoh M, Okuda S, Yoshizawa A, Kanehisa M. KAAS: an automatic genome annotation and pathway reconstruction server. Nucleic Acids Res. 2007;35:W182-5.

\section{Publisher's Note}

Springer Nature remains neutral with regard to jurisdictional claims in published maps and institutional affiliations.

Ready to submit your research? Choose BMC and benefit from:

- fast, convenient online submission

- thorough peer review by experienced researchers in your field

- rapid publication on acceptance

- support for research data, including large and complex data types

- gold Open Access which fosters wider collaboration and increased citations

- maximum visibility for your research: over $100 \mathrm{M}$ website views per year

At BMC, research is always in progress.

Learn more biomedcentral.com/submissions 